\title{
GJB2: Frequency of the Less Common Variants in a Sample of the Portuguese Population
}

\section{GJB2: Frequência das Suas Variantes Menos Comuns numa Amostra da População Portuguesa}

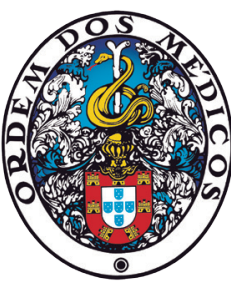

\author{
Cláudia Sousa REIS $\rrbracket^{1}$, Ana Cristina SANTOS ${ }^{2,3}$, Henrique BARROS ${ }^{2,3}$, Susana FERNANDES ${ }^{4,5}$, \\ Carla Pinto MOURA $4,5,6$ \\ Acta Med Port 2021 Sep;34(9):592-600 • https://doi.org/10.20344/amp.13781
}

\section{ABSTRACT}

Introduction: Sequence variants in the GJB2 gene account for up to $50 \%$ of cases of non-syndromic sensorineural hearing loss in the Caucasian population. In this study, we report the frequency of the less common variants of the GJB2 gene in a Portuguese sample and compare these frequencies with those of a group of hearing-impaired patients.

Material and Methods: In order to select the less common GJB2 variants, 147 hearing-impaired patients followed in Centro Hospitalar Universitário de São João were evaluated. Afterwards, the presence of those variants was tested in 360 individuals from Generation 21. Results: The patient assessment enabled the selection of 11 GJB2 variants. Of those, 10 were investigated in Generation 21 participants, with only four being detected, in heterozygosity: p.Phe83Leu, p.Arg127His, $p$.Val153lle and p.Asn206Ser, with the allelic frequencies (95\% confidence interval) of $0.14 \%(0.01 \%-0.87 \%), 0.28 \%(0.01 \%-1.08 \%), 0.97 \%(0.43 \%-2.04 \%)$ and $0.14 \%(0.01 \%$ $-0.88 \%)$, respectively. Two variants, $p$.Val37lle and $p$.Val95Met, were more frequent in the patients' group with statistical significance. Discussion: Our results allow for the $p$. Arg127His and $p$.Val153lle variants to comply with polymorphism criteria and support the pathogenicity of $p$.Val37lle and $p$.Val95Met variants. Moreover, two cases of moderate hearing loss were explained by the $p$.Val37lle/p. Asn206Ser genotype, substantiating both the pathogenicity of such variants and the hypothesis that compound heterozygosity with p.Ans206Ser is associated with mild-moderate genotypes.

Conclusion: Understanding the role of the variants is essential in order to provide genetic counselling to patients and their families. We explored a set of uncommon GJB2 variants that comprised $12 \%$ of the hearing-impaired patients in this study, supporting the relevance of their description.

Keywords: Connexin 26; Gene Frequency; Genetic Counselling; GJB2 protein, human; Hearing Loss, Sensorineural

\section{RESUMO}

Introdução: As mutações no gene GJB2 são responsáveis por mais de 50\% dos casos de hipoacusia neurossensorial não sindrómica na população caucasiana. Neste estudo, reporta-se a frequência das variantes menos comuns do gene GJB2 numa amostra da população portuguesa, comparando-se com a dos doentes com hipoacusia seguidos na consulta de Genética.

Material e Métodos: Para seleção das variantes menos frequentes do gene GJB2, avaliaram-se 147 doentes com hipoacusia seguidos na consulta de Genética - Doenças Hereditárias do Ouvido do Centro Hospitalar Universitário de São João. A presença dessas variantes foi depois testada em 360 indivíduos da Geração 21.

Resultados: A avaliação dos doentes com hipoacusia permitiu selecionar 11 variantes. Dessas, 10 foram pesquisadas nos indivíduos da Geração 21, identificando-se apenas quatro, em heterozigotia: $p$.Phe83Leu, $p$.Arg127His, $p$.Val153lle e $p$.Asn206Ser, com frequências alélicas (intervalo de confiança $95 \%)$ de $0,14 \%(0,01 \%-0,87 \%), 0,28 \%(0,01 \%-1,08 \%), 0,97 \%(0,43 \%-2,04 \%)$ e $0,14 \%(0,01 \%$ - 0,88\%), respetivamente. Duas variantes, p.Val37lle e p.Val95Met, mostraram-se mais frequentes nos doentes com hipoacusia de forma estatisticamente significativa.

Discussão: Estes resultados permitem considerar as variantes $p$.Arg127His e $p$.Val153lle como polimorfismos e apoiam a patogenicidade das variantes $p$.Val37lle e $p$.Val95Met. Note-se ainda que dois casos de hipoacusia moderada foram justificados pelo genótipo p.Val37Ile/p.Asn206Ser, apoiando a patogenicidade de tais variantes e corroborando a hipótese de que heterozigotias compostas com a p.Asn206Ser cursam com fenótipo ligeiro-moderado.

Conclusão: O conhecimento da patogenicidade das variantes é fundamental para o aconselhamento genético dos doentes e respetivas famílias. No seu conjunto, as variantes do gene GJB2 analisadas estavam presentes em $12 \%$ dos doentes, reiterando a relevância do seu estudo.

Palavras-chave: Aconselhamento Genético; Conexina 26; Frequência do Gene; Gene GJB2 humano; Perda Auditiva Neurossensorial

\section{INTRODUCTION}

Sensorineural hearing loss (SNHL) is one of the most common congenital sensory impairments, affecting approximately one in 500 - 1000 newborns. ${ }^{1}$ About $60 \%$ of cases of early-onset hearing loss are due to genetic causes, of which
$70 \%$ are non-syndromic. ${ }^{2}$ Non-syndromic sensorineural hearing loss (NS-SNHL) is inherited in an autosomal recessive trait in $80 \%$, but it can also be transmitted in autosomal dominant $(15 \%-20 \%)$, X-linked $(2 \%-3 \%)$, or mitochondrial

\footnotetext{
1. Faculty of Medicine. University of Porto. Porto. Portugal.

2. Department of Public Health and Forensic Sciences, and Medical Education. Faculty of Medicine. University of Porto. Porto. Portugal.

3. Instituto de Saúde Pública. Universidade do Porto. Porto. Portugal.

4. Genetics Unit. Department of Pathology. Faculty of Medicine. University of Porto. Centro Hospitalar Universitário de São João. Porto. Portugal.

5. Instituto de Investigação e Inovação em Saúde. Universidade do Porto. Porto. Portugal.

6. Department of Otorhinolaryngology. Centro Hospitalar Universitário de São João. Porto. Portugal.

$\triangle$ Autor correspondente: Cláudia Sousa Reis. claudia.casr@gmail.com

Recebido: 24 de março de 2020 - Aceite: 11 de janeiro de 2021 - First published: 25 de maio de 2021 - Online issue published: 01 de setembro de 2021 Copyright $\odot$ Ordem dos Médicos 2021
} 
(1\%) patterns. ${ }^{3}$

More than one hundred genes are known to be involved in NS-SNHL. Despite the genetic heterogeneity, sequence variants in the GJB2 gene account for up to $50 \%$ of cases of NS-SNHL in several populations. ${ }^{4}$ This gene encodes connexin 26 , which is the major component of gap junctions in the cochlea and has been implicated in the maintenance of $\mathrm{K}^{+}$homeostasis in the inner ear. ${ }^{1}$ More than two hundred GJB2 variants have been reported, most of them considered pathogenic. ${ }^{5}$ The p.Gly12Valfs*2 (also known as c.35delG) variant is the most common GJB2 mutation in several SNHL populations, including Portugal. ${ }^{3,6-9}$ The p.Met34Thr variant, recently classified as pathogenic, has also been found with a high frequency among SNHL patients..$^{3,9,10}$ The frequency of the p.Gly12Valfs ${ }^{*} 2$ and p.Met34Thr mutations in the general Portuguese population has already been estimated. ${ }^{11}$ As for the remaining GJB2 variants, no published studies in the Portuguese population have estimated their carrier rates.

The main purpose of this study was to estimate the frequency of the less common GJB2 variants in a Portuguese community sample - Generation 21 (G21) - and to compare these frequencies with those of SNHL patients. To select the less common GJB2 variants, a cohort of SNHL patients was evaluated.

We also compare the allelic frequencies of the G21 sample with those of the European sample of the GnomAD Exome population database. ${ }^{12}$

\section{MATERIAL AND METHODS SNHL patients}

A total of 147 consecutive patients followed in the Hereditary Hearing Loss Genetics Clinic from June 2011 until February 2019, presenting with mild to profound SNHL, were studied for GJB2 variants. For that purpose, peripheral blood samples were collected. Additionally, the audiological evaluation was performed using auditory brainstem response tests or pure tone audiometry. For each patient, the medical history has been collected to determine the age of onset and hearing loss evolution, family and patient history. Moreover, causes of acquired hearing loss were excluded. The severity of SNHL was classified by the pure tone average (PTA) of 0.5, 1, 2 and $4 \mathrm{kHz}$ thresholds: PTA $<20 \mathrm{~dB}$ was defined as normal hearing, $21-40 \mathrm{~dB}$ as mild SNHL, 41 - $70 \mathrm{~dB}$ as moderate SNHL, 71 - $95 \mathrm{~dB}$ as severe SNHL and PTA > $95 \mathrm{~dB}$ as profound SNHL.

\section{Selection of the less common variants}

The evaluation of the SNHL patients' cohort provided the spectrum and frequency of GJB2 variants in this group. Taking this spectrum as reference, every variant other than p.Gly12Valfs*2 (c.35delG) and p.Met34Thr was included in our set of less common variants - the target variants of this study. Then, the G21 cohort participants were screened for the selected GJB2 variants, in order to assess their frequency in this Portuguese community group.

\section{G21 cohort participants}

Generation 21 (G21), is a population-based birth cohort of 8647 newborns recruited in the metropolitan area of Porto, Portugal, in 2005 - 2006. The recruitment occurred at all level III public units providing obstetrical and neonatal care. At four years of age, the total cohort was invited to a reevaluation that occurred between April 2009 and July 2011. For this specific study, 480 of the participants attending the follow-up evaluation were randomly selected to study the carrier rate of the most common variants of the GJB2 gene. To fit into the general study aim, only children with parents of Portuguese nationality were included. For each child, a sample of buccal mucosa cells was collected with a swab. Of the 480 selected participants, only 360 were included in the study, due to sample quality constraints.

\section{Genetic analysis}

In total, 360 DNA samples were completely sequenced and analyzed. Firstly, genomic DNA was extracted from buccal mucosa cells, using a commercial kit (JETQUICK, Genomed). Then GJB2 gene Sanger sequencing was performed. For that purpose, polymerase chain reaction (PCR) of the GJB2 exon 2 was performed, using the following specific primer pair - Cx26F: 5'-TCTTTTCCAGAGCAAACCGCC-3' and Cx26R: 5'-TGAGCACGGGTTGCCTCATC-3'. $\mathrm{PCR}$ products purification using AmpureX ${ }^{\circledR}$ was performed to remove the contaminants. The sequencing analysis of amplified fragments was performed on an automated sequencer (Applied Biosystems ${ }^{\circledR} 3730 x$ I DNA Analyzer) and the Applied Biosystems ${ }^{\circledR}$ Sequencing Analysis v.5.4 software was used. The annotation of GJB2 sequence variants was based on the GenBank cDNA reference sequence NM_004004 and following the standard nomenclature recommended by the Human Genome Variation Society.

All phases of the study complied with the Ethical Principles for Medical Research Involving Human Subjects expressed in the Declaration of Helsinki (World Medical Association, 2013). The study was approved by the Centro Hospitalar Universitário de São João Ethics Committee and a signed informed consent according to the Declaration of Helsinki was obtained from all participants.

\section{Statistical analysis}

The statistical analysis was performed using GraphPad ${ }^{\circledR}$ and OpenEpi ${ }^{\circledR}$ software. Confidence intervals $(\mathrm{Cl})$ were calculated using the modified Wald method. ${ }^{13}$ Differences in the allelic frequencies between the G21 and the SNHL groups were tested by Fisher's exact test, as expected values in some cells of the contingency table were below five and the sample size was small. The chi-square test was used to assess differences between the allelic frequencies of the G21 group and the data from the European sample of the GnomAD Exome population database. ${ }^{12} \mathrm{~A}$ significance level of 0.05 was considered. 


\section{RESULTS}

GJB2 variants in patients with SNHL

A total of 147 index cases with mild to profound SNHL were studied for the presence of variants in the GJB2 gene. p.Gly12Valfs*2 (also known as c.35delG) and p.Met34Thr were the most frequently identified variants and were previously studied by Dória $\mathrm{M}$ et al. ${ }^{11}$ Besides those, other 11 less common variants were identified: p.lle20Met, p.Trp24X, p.lle30Val, p.Val37lle, p.Phe83Leu, p.Val95Met, p.Arg127His, p.Arg143GIn, p.Val153lle, p.Arg184Trp and p.Asn206Ser. Together, these 11 less common variants were found in 18 of the 147 families included. The allelic frequencies and genotypes are described in Table 1.

\section{Frequency of the less common vari-} ants in the $\mathbf{G} 21$ group

A total of 360 individuals from the G21 cohort were studied for the presence of the less common variants identified in patients with SNHL. Due to poor DNA amplification by PCR at the extremities of exon 2 of the GJB2 gene, the p.lle20Met variant was not possible to study, reducing the total number of variants assessed to ten. For the same reason, some of the G21 samples could not be screened for the presence of $p$.Trp24Ter, p.Arg184Trp and p.Asn206Ser variants, and hence the total number of subjects screened for these variants was 328, 359 and 352 , respectively.

Four out of the ten variants assessed have been identified, in heterozygosity, in individuals from the G21. The allelic frequencies are summarized in Table 1. The $p$.Val153lle variant was found in seven individuals, indicating a carrier rate of approximately 1 in 51 (1.94\%, 95\% Cl 0.86\% - 4.04\%). The p.Arg127His variant was detected in two more participants, indicating a carrier rate of 1 in $180(0.56 \%, 95 \% \mathrm{Cl} 0.02 \%$ - $2.14 \%$ ). One individual presented the p.Phe83Leu variant, indicating a carrier rate of 1 in $360(0.28 \%, 95 \% \mathrm{Cl} 0.01 \%$ - $1.72 \%$ ). Likewise, the p.Asn206Ser variant was found in one participant, suggesting a carrier rate of 1 in 352 $(0.28 \%, 95 \% \mathrm{Cl} 0.01 \%-1.76 \%)$.

No homozygotes or compound

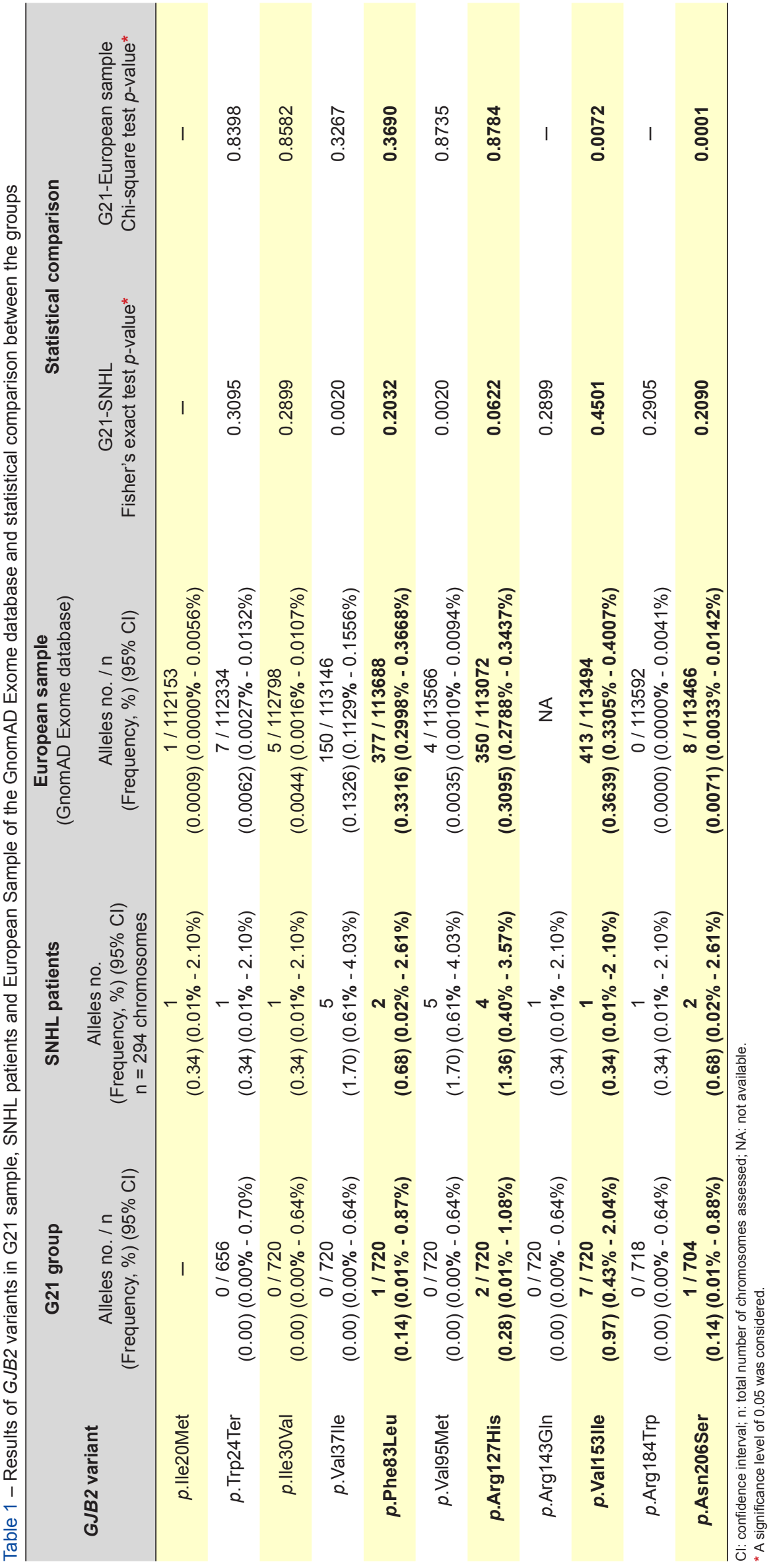


heterozygotes were found for any of the variants. The p. Trp24Ter, p.lle30Val, p.Val37Ile, p.Val95Met, p.Arg143GIn and $p$. Arg184Trp variants were not identified in the cohort.

\section{Comparison between the G21 group and SNHL patients}

We compared the allelic frequencies in the G21 group with those of SNHL patients. The differences in the allelic frequencies between the two groups were statistically significant for the $p$.Val37lle and the $p$.Val95Met variants ( $p$ $=0.0020)$, these variants being present only in the SNHL group. Regarding the other variants, no statistically significant differences were found $(p>0.05)$. The statistical results are presented in Table 1.

\section{Comparison between the G21 group and the European sample of the GnomAD Exome}

We compared the G21 group allelic frequencies with those of the GnomAD Exome for a (non-Finnish) European sample. ${ }^{12}$ The differences were statistically significant for $p$.Val153lle $(p=0.0072)$ and $p$.Asn206Ser $(p<0.0001)$ variants, with these variants being more frequent in the G21 sample. No statistically significant differences were found for any of the other variants $(p>0.05)$. The allelic frequencies of the GJB2 variants in the GnomAD European sample, as well as the statistical results, are presented in Table 1.

\section{Characterization of p.Phe83Leu, p.Arg127His, p.Val153lle and p.Asn206Ser variants in families with NS-SNHL}

The p.Phe83Leu, p.Arg127His, p.Val153lle and p.Asn206Ser variants correspond the ones that were identified in the G21 sample. In order to further characterize them, we report on the NSHL patients and respective families in which they were present, corresponding to a total of seven unrelated families. The families' genograms with the individuals' genotypes and phenotypes are presented in Fig. 1.

Syndromic hearing loss was evaluated for all hearingimpaired members. Subjects presenting other clinical findings beyond hearing loss were further studied using complementary diagnostics tests and were observed by other medical specialists when required. No individual fulfilled the criteria for syndromic hearing loss. Also, none of them com-
Family 1

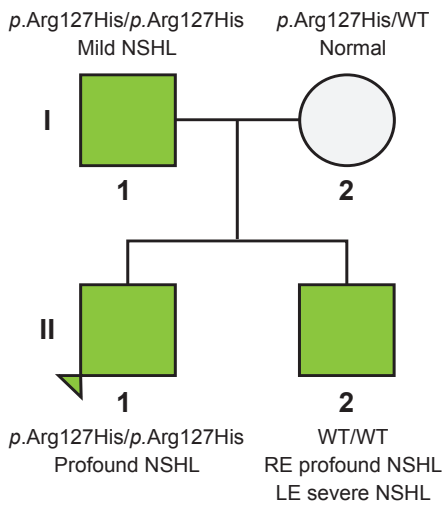

Family 2

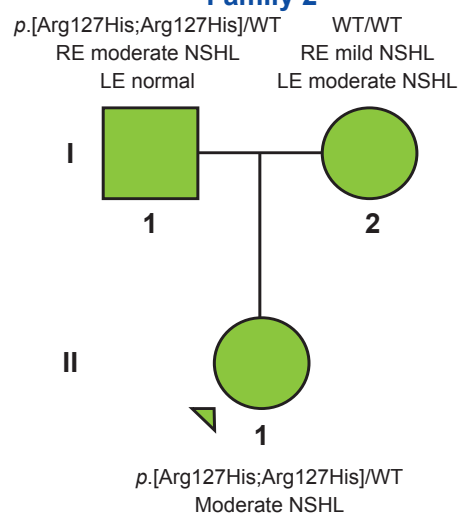

Family 3

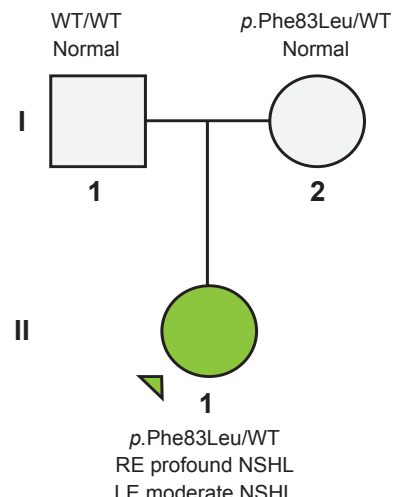

Family 4

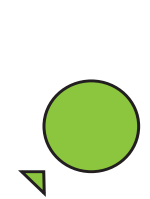

p.Phe83Leu/WT

RE mild NSHL

LE moderate NSHL
Family 5

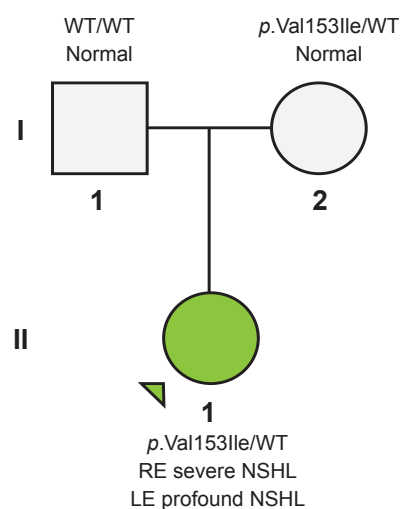

Family 6

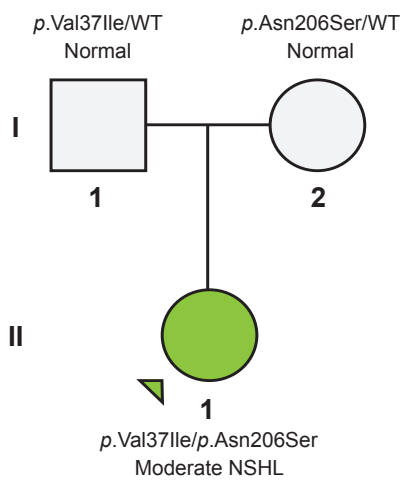

Family 7

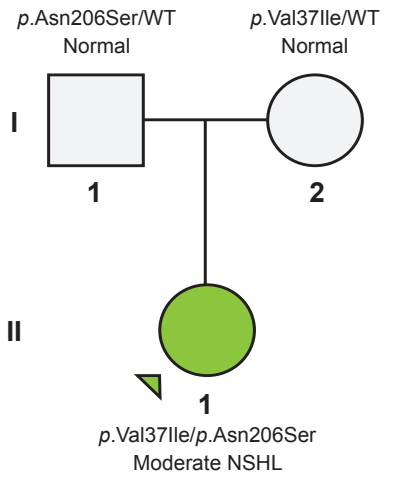

Figure 1 - Genogram of the seven families. Hearing-impaired symptomatic individuals are indicated by green symbols, unaffected patients by light grey symbols. The severity of SNHL considering the PTA $\mathrm{P}_{0 ., 1,2,4 \mathrm{kHz}}$ is presented: normal hearing corresponds to a PTA $<20 \mathrm{~dB}$, mild SNHL to $21-40 \mathrm{~dB}$, moderate SNHL to $41-70 \mathrm{~dB}$, severe SNHL to $71-95 \mathrm{~dB}$ and profound SNHL to PTA $>95 \mathrm{~dB}$. The index case is identified by a green arrow.

WT: wild type; NSHL: non-syndromic hearing loss; RE: right ear; LE: left ear 
plained of dizziness or tinnitus, nor reported barotrauma or occupational, recreational, or accidental noise exposure. Some individuals had history of otological disease. Clinical features are summarized in Table 2. Parents from families one, two and four were consanguineous. Also, families one and two were of Romani ethnicity.

The p.Phe83Leu variant was present in the heterozygous state in families three and four. Since NS-SNHL is mostly of autosomal recessive inheritance, it is unlikely that this variant is the cause of the condition. Furthermore, in family three, the mother of the index case has the same GJB2 genotype and normal hearing.

The p.Arg127His variant was identified in patients from two different families, both Romani - families one and two - either in heterozygosity or homozygosity or cis configuration of two p.Arg127His variants. The cis configuration was inferred in individuals $\mathrm{I}-1$ and II-1 from family two since the individual II-1 inherited both variants from the male progenitor. The p.Arg127His variant does not seem to segregate with the hearing impairment, as the individual II-2 in family one presented with severe to profound NS-SNLH despite the absence of this variant.

The p.Val153lle variant was found in heterozygosity in two individuals from family five. Following the same line of reasoning used for the $p$.Phe83Leu variant, it is unlikely that this variant is the cause of the hearing impairment.

The p.Asn206Ser variant was found in compound heterozygosity with the $p$.Val37lle variant in two individuals from families six and seven, both presenting moderate NSSNHL bilaterally. Families six and seven are not related, but both came from the same region of southern Portugal. As both variants are classified as pathogenic, this compound heterozygosity might be responsible for the hearing loss in these patients. ${ }^{14,15}$

\section{DISCUSSION}

In this study, 360 participants from the G21 cohort were screened for the presence of ten less common GJB2

Table 2 - Clinical characteristics of individuals from the SNHL families harbouring the variants $p$.Phe83Leu, p.Arg127His, $p$.Val153lle and p.Asn206Ser. The severity of SNHL considering the PTA ${ }_{0.5,1,2,4 \mathrm{kHz}}$ is presented: normal hearing corresponds to a PTA $<20 \mathrm{~dB}$, mild SNHL to $21-40 \mathrm{~dB}$, moderate SNHL to $41-70 \mathrm{~dB}$, severe SNHL to $71-95 \mathrm{~dB}$ and profound SNHL to PTA $>95 \mathrm{~dB}$.

\begin{tabular}{|c|c|c|c|c|c|c|}
\hline Family & Case & $\begin{array}{c}\text { Age } \\
\text { (years) }\end{array}$ & $\begin{array}{c}\text { Age at SNHL } \\
\text { onset }\end{array}$ & Hearing impairment & Genotype & Observation \\
\hline \multirow{4}{*}{$1^{*} \dagger$} & $\mathrm{I}-1$ & 54 & & Bilateral mild & p.Arg127His/p.Arg127His & - \\
\hline & $\mathrm{I}-2$ & 47 & - & Normal audition & p.Arg127His/WT & - \\
\hline & $\|-1$ & 24 & 18 months & Bilateral profound & p.Arg127His/p.Arg127His & Bilateral prosthesis \\
\hline & $\|-2$ & 17 & 16 months & $\begin{array}{l}\text { RE profound and } \\
\text { LE severe }\end{array}$ & WT/WT & RE cochlear implant \\
\hline \multirow[b]{3}{*}{$2^{*} \dagger$} & $\mathrm{I}-1$ & 58 & - & $\begin{array}{l}\text { RE mixed moderate } \\
\text { and LE normal }\end{array}$ & p. [Arg127His;Arg127His]/WT & RE chronic otitis media \\
\hline & $\mathrm{I}-2$ & 50 & - & $\begin{array}{c}\mathrm{RE} \text { mild and } \\
\text { mixed moderate LE }\end{array}$ & WT/WT & LE tympanosclerosis \\
\hline & II-1 & 20 & 6 years & Bilateral mixed moderate & p. [Arg127His;Arg127His]/WT & $\begin{array}{l}\text { Bilateral prosthesis; } \\
\text { LE chronic otitis media; } \\
\text { RE tympanoplasty; } \\
\text { Bilateral myringotomy } \\
\text { and tubes at } 4 \text { - } 5 \text { yo. }\end{array}$ \\
\hline \multirow{3}{*}{3} & $\mathrm{I}-1$ & 56 & - & Normal audition & WT/WT & - \\
\hline & $\mathrm{I}-2$ & 54 & - & Normal audition & p.Phe83Leu/WT & - \\
\hline & II-1 & 32 & Childhood & $\begin{array}{l}\text { RE profound and LE } \\
\text { moderate }\end{array}$ & p.Phe83Leu/WT & LE prosthesis \\
\hline $4^{*}$ & - & 5 & Congenital & RE mild and LE moderate & p.Phe83Leu/WT & Bilateral prosthesis \\
\hline \multirow{3}{*}{5} & $\mathrm{I}-1$ & 69 & - & Normal audition & WT/WT & - \\
\hline & $\mathrm{I}-2$ & 64 & - & Normal audition & p.Val153lle/WT & - \\
\hline & II-1 & 41 & 1 year & $\begin{array}{l}\text { RE severe and } \\
\text { LE profound }\end{array}$ & p.Val153lle/WT & - \\
\hline \multirow{3}{*}{6} & $\mathrm{I}-1$ & 34 & - & Normal audition & p.Val37Ile/WT & - \\
\hline & $\mathrm{I}-2$ & 35 & - & Normal audition & p.Asn206Ser/WT & - \\
\hline & $\|-1$ & 3 & Congenital & Bilateral moderate & p.Val37lle/p.Asn206Ser & Bilateral prosthesis \\
\hline \multirow{3}{*}{7} & $\mathrm{I}-1$ & 50 & - & Normal audition & p.Asn206Ser/WT & - \\
\hline & $1-2$ & 42 & - & Normal audition & p.Val37Ile/WT & - \\
\hline & II-1 & 7 & 18 months & Bilateral moderate & p.Val37Ile/p.Asn206Ser & Bilateral prosthesis \\
\hline
\end{tabular}


variants: p.lle20Met, p.Trp24X, p.lle30Val, p.Val37lle, p.Phe83Leu, p.Val95Met, p.Arg127His, p.Arg143GIn, p.Val153lle, p.Arg184Trp and p.Asn206Ser. These variants were selected through the evaluation of a cohort of 147 SNHL patients who had been screened for GJB2 variants; every detected variant other than p.Gly12Valfs*2 (c.35delG) and p.Met34Thr was included in our set of less common variants. Even though each less common variant was present in few patients, together they comprised approximately $12 \%$ of the SNHL patients included in this study, denoting the relevance in approaching them. An important tool for the classification of the variants regarding pathogenicity is the assessment of their frequency in a healthy population. To our knowledge, this is the first study to estimate the frequency of these variants in a Portuguese community sample.

Four out of ten less common variants were found in individuals from the G21 cohort: p.Phe83Leu, p.Arg127His, $p$.Val153lle and $p$. Asn206Ser. All four are missense variants and are classified as benign/likely benign, ${ }^{16}$ benign/likely benign/uncertain significance, ${ }^{17}$ likely benign, ${ }^{18}$ and pathogenic, ${ }^{14}$ respectively. Differences between the allelic frequencies of these variants in the G21 sample and the SNHL group were not statistically significant - a finding which was expected for p.Phe83Leu, p.Arg127His and p.Val153lle, considering their tendentiously benign classifications, but not for p.Asn206Ser, whose pathogenicity would be better described by a higher frequency in the SNHL group compared to the G21 sample. For the p.Arg127His variant, however, a right deviation of the $\mathrm{Cl}$ of the $\mathrm{SNHL}$ group was observed, suggesting a higher frequency in this group. An explanation can be the fact that the SNHL group also included Romani people, while the G21 group included only participants with Portuguese ancestry. In fact, both index cases identified with the p.Arg127His variant were Romani. Similarly, in another Portuguese study consisting of a report on three Portuguese families carrying this variant, two of the families were also Romani. ${ }^{19}$ Romani people have Indian ancestry and this variant was found at a high frequency in Indian individuals. ${ }^{20}$ Also, in a study with Slovak Romani hearing impaired people, p.Arg127His was the most common GJB2 variant, occurring in $19.4 \%$ of the chromosomes screened. ${ }^{21}$ So, the inclusion of Romani people may explain the trend for a higher allelic frequency in the SNHL group.

A key point to mention is that the highest estimate for the allelic frequencies of $p$.Arg127His and $p$.Val153lle variants in the G21 sample is higher than 1\%, allowing for these variants to comply with polymorphism criteria. The role of the p.Arg127His variant in SNHL is contentious as functional studies are inconsistent. ${ }^{22-25}$ Evidence of its possible nonpathogenic nature relies on its common occurrence in the Indian population and the similar frequencies between hearing and non-hearing subjects found in France. ${ }^{7,20}$ Moreover, the $p$.Arg127His variant has been detected in normal hearing subjects both at homozygous state ${ }^{7,26}$ and in compound heterozygosity with the p.Gly12Valfs*2 mutation. ${ }^{27} \mathrm{Nev}$ ertheless, two studies report significantly higher frequen- cies in the patient group compared to the control group, one from Tibet $^{28}$ and the other from India. ${ }^{29}$ In the Indian study, compound heterozygosity involving the $p . A r g 127 \mathrm{His}$ variant was identified in hearing-impaired individuals but not among control individuals. ${ }^{29}$ In this regard, some studies suggest that genotypes combining $p . A r g 127 \mathrm{His}$ variant with other pathogenic variants could lead to hearing loss by having phenotypic expression modulated by environmental factors or modifier genes. ${ }^{7,19,29}$ Regarding the $p$.Val153lle variant, the possibility of being pathogenic has been previously proposed. ${ }^{30-33}$ However, subsequent studies contradicted this hypothesis by reporting its high occurrence in normal hearing populations, ${ }^{20,34}$ and describing its presence in normal hearing subjects both at the homozygous state $\mathrm{e}^{20,35}$ and in compound heterozygosity with the p.Gly12Valfs*2 (35delG) mutation. ${ }^{27,34}$ Finally, in vitro expression studies in transfected HeLa cells demonstrated that the mutated p.Val153lle protein was correctly synthesized and targeted to the plasma membrane and its function was not altered..$^{35}$ It is noteworthy that some studies do not rule out the possible role of the $p$.Val153lle variant as a modifier of the final phenotype in the presence of other mutations in genes involved in hearing function. ${ }^{30,32}$

The p.Phe83Leu variant was first described in $1998^{36}$ and since then, it has been reported by several authors as a polymorphism, as similar frequencies in affected individuals and controls have been observed - likewise in the present study - and, in familial studies, it was not segregating with SNHL. ${ }^{37-42}$ Furthermore, functional evidence supports its non-pathogenic nature. ${ }^{43}$

In this study, the p.Ans206Ser variant was detected in two index cases and, interestingly, both presented compound heterozygosity with the pathogenic variant p.Val37lle. ${ }^{44}$ Also, both children had bilateral moderate NSSNHL $\left(P^{2} A_{0.5,1,2,4 \mathrm{kHz}}\right.$ in the range of $\left.41-70 \mathrm{~dB}\right)$. Compound heterozygous genotypes with p.Asn206Ser have received special attention in previous studies, as they have been associated with less severe audiological characteristics. ${ }^{45}$ In fact, the genotype $p$.Val37lle/p.Ans206Ser was previously identified in a patient with congenital bilateral mild NSSNHL (PTA ${ }_{0.5,1,2 \mathrm{kHz}}$ of $\left.24 \mathrm{~dB}\right) .{ }^{33}$ Furthermore, the genotype p.Gly12Valfs ${ }^{2} 2 / p$.Ans206Ser was associated with bilateral moderate SNHL in three patients PTA $_{0.5,1,2,3,4,6,8 \mathrm{kHz}}$ in the range of $41-70 \mathrm{~dB}^{7}$; $\mathrm{PTA}_{0.5,1,2 \mathrm{kHz}}$ in the range of $41-55$ $\mathrm{dB}^{46}$ and PTA $\mathrm{P}_{0.5,1,2,4 \mathrm{kHz}}$ of $\left.65 \mathrm{~dB}\right)^{47}$ and unilateral mild SNHL in another $\left(\mathrm{PTA}_{0.5,1,2 \mathrm{kHz}}\right.$ in the range of $\left.21-40 \mathrm{~dB}\right) .{ }^{46}$ These findings led the authors to speculate that the p.Asn2016Ser variant may not severely compromise the gap junctional communication system in the inner ear, ${ }^{46}$ which was later corroborated by functional studies - some even revealing that the permeability to anionic fluorescent tracers was maintained, but the permeability to larger molecules was compromised. ${ }^{31,48,49}$

The comparison between the allelic frequencies of the G21 group and the GnomAD European sample revealed statistically significant differences for the $p$.Val153lle and p.Asn206Ser variants, suggesting that these variants might 
be more frequent in the Portuguese population. In fact, our allelic rate for $p$.Val153lle $(0.97 \%)$ is higher than the frequencies described for Italy $(0.49 \%)^{35}$ and France $(0.38 \%),{ }^{7}$ but lower than that for the Czech Republic (1.92\%). ${ }^{34}$ Variants p.Phe83Leu and p.Arg127His variant did not show statistically significant differences, even though our G21 allelic frequencies $(0.14 \%$ for $p$.Phe 83 Leu and $0.28 \%$ for p.Arg127His) were lower than frequencies described for France $\left(0.28 \%\right.$ and $0.66 \%$, respectively). ${ }^{7}$

Another important consideration of our study is the detection of the Arg127His variant in a cis configuration (family 2, Fig.1) since it has never been described in previous research, as far as we know.

The variants $p$.Trp24Ter, $p$.Val37lle and $p$.Arg184Trp, classified as pathogenic, ${ }^{15,50,51}$ and the variants $p$.Val95Met and $p . A r g 143 \mathrm{GIn}$, classified as pathogenic/likely pathogenic, ${ }^{52,53}$ were not identified in individuals from the G21 cohort, which is consistent with their classifications. The p.lle30Val, a variant of uncertain significance, ${ }^{54}$ was not detected either. The differences in allelic frequencies between the G21 and the SNHL groups for the $p$.Val37lle and the $p$.Val95Met variants were statistically significant, strengthening the hypothesis of their pathogenic role in SNHL. No statistically significant differences were observed for the other variants.

\section{CONCLUSION}

The present study is the first report of the frequency of the less common GJB2 variants in a Portuguese sample. The p.Phe83Leu, p.Arg127His, p.Val153lle and p.Asn206Ser variants were identified in G21 participants, in heterozygosity, with the allelic frequencies of $0.14 \%, 0.28 \%, 0.97 \%$ and $0.14 \%$, respectively. The $p$.Trp24Ter, $p$.lle30Val, $p$.Val37lle, $p$. Val95Met, $p . A r g 143 \mathrm{GIn}$ and $p$. Arg184Trp variants were not found in the G21 group. Our estimate of the allelic frequencies allows for the $p$.Arg127His and $p$.Val153lle variants to comply with polymorphism criteria. Furthermore, our comparison of the allelic frequencies of the variants between G21 and the patients' group strengthens the hypothesis of $p$.Val37lle and the $p$.Val95Met variants having a pathogenic role in NS-SNHL. Moreover, these results raise the hypothesis that $p$.Val153lle and $p$. Asn206Ser variants are more frequent in the northern Portuguese population than in the general European population. Estimating the carrier rates of the variants in a healthy population is an important tool for the classification of their pathogenicity. The clarification of the pathogenic role of each variant is of paramount importance in familial genetic counselling.

\section{REFERENCES}

1. Morton CC, Nance WE. Newborn hearing screening - a silent revolution. N Engl J Med. 2006;354:2151-64

2. Lameiras AR, Gonçalves AC, Santos R, O'Neill A, Reis LR dos, Matos TD, et al. The controversial p.Met34Thr variant in GJB2 gene: two siblings, one genotype, two phenotypes. Int J Pediatr Otorhinolaryngol. 2015;79:1316-9.

3. Nogueira C, Coutinho M, Pereira C, Tessa A, Santorelli FM, Vilarinho L. Molecular investigation of pediatric portuguese patients with sensorineural hearing loss. Genet Res Int. 2011;2011:587602.

4. Kenneson A, Van Naarden Braun K, Boyle C. GJB2 (connexin 26)

\section{AUTHORS CONTRIBUTION}

CSR: Data analysis and interpretation; draft of the manuscript.

ACS, HB: Cohort design and management; critical review of the paper.

SF: Design of the work; data interpretation; critical review of the paper.

CPM: Design of the work; data interpretation; critical review of the paper; approval of the final version.

\section{ACKNOWLEDGMENTS}

We are grateful to João Paulo Oliveira for the technical help in population genetics and discussion of the results. The authors also gratefully acknowledge the families enrolled in Generation XXI, all members of the research team, and the participating hospitals and their staff.

\section{PROTECTION OF HUMANS AND ANIMALS}

The authors declare that the procedures were followed according to the regulations established by the Clinical Research and Ethics Committee and to the 2013 Helsinki Declaration of the World Medical Association.

\section{DATA CONFIDENTIALITY}

The authors declare having followed the protocols in use at their working center regarding patients' data publication.

\section{COMPETING INTERESTS}

The authors have declared that no competing interests exist.

\section{FUNDING SOURCES}

Generation XXI was funded by Programa Operacional de Saúde - Saúde XXI, Quadro Comunitário de Apoio III and Administração Regional de Saúde Norte (Regional Department of Ministry of Health). This study was funded by FEDER through the Operational Programme Competitiveness and Internationalization and national funding from the Foundation for Science and Technology - FCT (Portuguese Ministry of Science, Technology and Higher Education) by the Unidade de Investigação em Epidemiologia - Instituto de Saúde Pública da Universidade do Porto (EPIUnit) (POCl-01-0145-FEDER-006862; Ref. UID/DTP/ 04750/2013), and the Calouste Gulbenkian Foundation. Ana Cristina Santos holds an FCT Investigator contract IF/ 01060/2015. (POCl- 01-0145-FEDER-016837). variants and nonsyndromic sensorineural hearing loss: a HuGE review. Genet Med. 2002;4:258-74.

5. Stenson PD, Mort M, Ball EV, Howells K, Phillips AD, Thomas NS, et al. The Human Gene Mutation Database: 2008 update. Genome Med. 2009;1:13.

6. Pandya A, Arnos KS, Xia XJ, Welch KO, Blanton SH, Friedman TB, et al. Frequency and distribution of GJB2 (connexin 26) and GJB6 (connexin 30 ) mutations in a large North American repository of deaf probands. Genet Med. 2003;5:295-303.

7. Roux AF, Pallares-Ruiz N, Vielle A, Faugère $V$, Templin $C$, Leprevost $D$, 
et al. Molecular epidemiology of DFNB1 deafness in France. BMC Med Genet. 2004;5:5.

8. Dalamón $\mathrm{V}$, Lotersztein $\mathrm{V}$, Béhèran $\mathrm{A}$, Lipovsek $\mathrm{M}$, Diamante $\mathrm{F}$, Pallares $\mathrm{N}$, et al. GJB2 and GJB6 genes: molecular study and identification of novel GJB2 mutations in the hearing-impaired Argentinean population. Audiol Neurootol. 2010;15:194-202.

9. Matos TD, Simões-Teixeira H, Caria H, Gonçalves AC, Chora J, Correia $\mathrm{M}$ do $\mathrm{C}$, et al. Spectrum and frequency of GJB2 mutations in a cohort of 264 Portuguese nonsyndromic sensorineural hearing loss patients. Int J Audiol. 2013;52:466-71.

10. Kelsell DP, Dunlop J, Stevens HP, Lench NJ, Liang JN, Parry G, et al. Connexin 26 mutations in hereditary non-syndromic sensorineural deafness. Nature. 1997;387:80-3.

11. Dória $M$, Neto AP, Santos AC, Barros $H$, Fernandes S, Moura CP. Prevalence of $35 \mathrm{del}$ and Met34Thr GJB2 variants in Portuguese samples. Int J Pediatr Otorhinolaryngol. 2015;79:2187-90.

12. Karczewski KJ, Francioli LC, Tiao G, Cummings BB, Alföldi J, Wang Q, et al. Variation across 141,456 human exomes and genomes reveals the spectrum of loss-of-function intolerance across human protein-coding genes. BioRxiv. 2019:531210.

13. Agresti A, Coull BA. Approximate is Better than "Exact" for linterval estimation of binomial proportions. Am Stat. 1998;52:119-26.

14. ClinVar. Bethesda: U.S. National Library of Medicine, National Center for Biotechnology Information; c2019-12. NM_004004.6(GJB2):c.617A>G (p.Asn206Ser). [accessed 2019 Jan 7]. Available from: https://www.ncbi. nlm.nih.gov/clinvar/variation/44763/.

15. ClinVar. Bethesda: U.S. National Library of Medicine, National Center for Biotechnology Information; c2019-12. NM_004004.6(GJB2):c.109G>A (p.Val37lle). [accessed 2019 Jan 7]. Available from: https://www.ncbi. nlm.nih.gov/clinvar/variation/17023/.

16. ClinVar. Bethesda: U.S. National Library of Medicine, National Center for Biotechnology Information; c2019-12. NM_004004.6(GJB2):c.249C>G (p.Phe83Leu). [accessed 2019 Jan 7]. Available from: https://www.ncbi. nlm.nih.gov/clinvar/variation/44732/.

17. ClinVar. Bethesda: U.S. National Library of Medicine, National Center for Biotechnology Information; c2019-12. NM_004004.6(GJB2):c.380G>A (p.Arg127His). [accessed 2019 Jan 7]. Available from: https://www.ncbi. nlm.nih.gov/clinvar/variation/44745/.

18. ClinVar. Bethesda: U.S. National Library of Medicine, National Center for Biotechnology Information; c2019-12. NM_004612.4(TGFBR1):c.457G>A (p.Val153lle). [accessed 2019 Jan 7]. Available from: https://www.ncbi.nlm.nih.gov/clinvar/ variation/213868/.

19. Matos TD, Simões-Teixeira H, Caria H, Rosa H, O'Neill A, Fialho G. The controversial p.Arg127His mutation in GJB2: report on three Portuguese hearing loss family cases. Genet Test Mol Biomarkers. 2010;14:141-4.

20. RamShankar M, Girirajan S, Dagan O, Ravi Shankar HM, Jalvi R, Rangasayee R, et al. Contribution of connexin26 (GJB2) mutations and founder effect to non-syndromic hearing loss in India. J Med Genet. 2003;40:e68

21. Minárik G, Ferák V, Feráková $E$, Ficek $A$, Poláková $H$, Kádasi L. High frequency of GJB2 mutation W24X among Slovak Romany (Gypsy) patients with non-syndromic hearing loss (NSHL). Gen Physiol Biophys. 2003;22:549-56.

22. Thönnissen E, Rabionet $R$, Arbonès ML, Estivill X, Willecke K, Ott T. Human connexin26 (GJB2) deafness mutations affect the function of gap junction channels at different levels of protein expression. Hum Genet. 2002;111:190-7.

23. D’Andrea P, Veronesi V, Bicego M, Melchionda S, Zelante L, Di lorio E, et al. Hearing loss: frequency and functional studies of the most common connexin26 alleles. Biochem Biophys Res Commun. 2002;296:685-91.

24. Wang HL, Chang WT, Li AH, Yeh TH, Wu CY, Chen MS, et al. Functional analysis of connexin-26 mutants associated with hereditary recessive deafness. J Neurochem. 2003;84:735-42.

25. Palmada M, Schmalisch K, Böhmer C, Schug N, Pfister M, Lang F, et al Loss of function mutations of the GJB2 gene detected in patients with DFNB1-associated hearing impairment. Neurobiol Dis. 2006;22:112-8.

26. Dahl HH, Tobin SE, Poulakis Z, Rickards FW, Xu X, Gillam L, et al. The contribution of GJB2 mutations to slight or mild hearing loss in Australian elementary school children. J Med Genet. 2006;43:850-5.

27. Marlin S, Garabédian ÉN, Roger G, Moatti L, Matha N, Lewin P, et al. Connexin 26 gene mutations in congenitally deaf children: pitfalls for genetic counseling. Arch Otolaryngol Head Neck Surg. 2001;127:92733

28. Yuan Y, Zhang X, Huang S, Zuo L, Zhang G, Song Y, et al. Common molecular etiologies are rare in nonsyndromic Tibetan Chinese patients with hearing impairment. PLoS ONE. 2012;7:e30720.

29. Adhikary B, Ghosh S, Paul S, Bankura B, Pattanayak AK, Biswas S, et al. Spectrum and frequency of GJB2, GJB6 and SLC26A4 gene mutations among nonsyndromic hearing loss patients in eastern part of India. Gene. 2015;573:239-45.

30. Wu BL, Lindeman N, Lip V, Adams A, Amato RS, Cox G, et al. Effectiveness of sequencing connexin 26 (GJB2) in cases of familial or sporadic childhood deafness referred for molecular diagnostic testing. Genet Med. 2002;4:279-88.

31. Meşe G, Londin E, Mui R, Brink PR, White TW. Altered gating properties of functional Cx26 mutants associated with recessive non-syndromic hearing loss. Hum Genet. 2004;115:191-9.

32. Dalamón $V$, Béhèran $A$, Diamante $F$, Pallares $N$, Diamante $V$, Elgoyhen $A B$. Prevalence of GJB2 mutations and the del(GJB6-D13S1830) in Argentinean non-syndromic deaf patients. Hear Res. 2005;207:43-9.

33. Snoeckx RL, Huygen PL, Feldmann D, Marlin S, Denoyelle F, Waligora J, et al. GJB2 mutations and degree of hearing loss: a multicenter study. Am J Hum Genet. 2005;77:945-57

34. Seeman $P$, Malíková M, Rasková D, Bendová O, Groh D, Kubálková $M$, et al. Spectrum and frequencies of mutations in the GJB2 (Cx26) gene among $156 \mathrm{Czech}$ patients with pre-lingual deafness. Clin Genet. 2004;66:152-7

35. Guerci VI, Grasso DL, Morgutti M, Amoroso A, D'Andrea P, Bicego M, et al. Connexin 26 gene: defining the role of the V1531 mutation. Hear Balance Commun. 2007;5:200-6.

36. Scott DA, Kraft ML, Carmi R, Ramesh A, Elbedour K, Yairi Y, et al. Identification of mutations in the connexin 26 gene that cause autosomal recessive nonsyndromic hearing loss. Hum Mutat. 1998;11:387-94.

37. Tang HY, Fang P, Ward PA, Schmitt E, Darilek S, Manolidis S, et al. DNA sequence analysis of GJB2, encoding connexin 26: observations from a population of hearing impaired cases and variable carrier rates, complex genotypes, and ethnic stratification of alleles among controls. Am J Med Genet A. 2006;140:2401-15.

38. Cheng X, Li L, Brashears S, Morlet T, Ng SS, Berlin C, et al. Connexin 26 variants and auditory neuropathy/dys-synchrony among children in schools for the deaf. Am J Med Genet A. 2005;139:13-8.

39. Santos RL, Aulchenko YS, Huygen PL, van der Donk KP, de Wijs IJ, Kemperman $\mathrm{MH}$, et al. Hearing impairment in Dutch patients with connexin 26 (GJB2) and connexin 30 (GJB6) mutations. Int J Pediatr Otorhinolaryngol. 2005;69:165-74.

40. Heathcote K, Syrris P, Carter ND, Patton MA. A connexin 26 mutation causes a syndrome of sensorineural hearing loss and palmoplantar hyperkeratosis (MIM 148350). J Med Genet. 2000;37:50-1.

41. Rabionet R, Zelante L, López-Bigas N, D’Agruma L, Melchionda S, Restagno $\mathrm{G}$, et al. Molecular basis of childhood deafness resulting from mutations in the GJB2 (connexin 26) gene. Hum Genet. 2000;106:40-4.

42. Picciotti PM, Pietrobono R, Neri G, Paludetti G, Fetoni AR, Cianfrone $F$, et al. Correlation between GJB2 mutations and audiological deficits: personal experience. Eur Arch Otorhinolaryngol. 2009;266:489-94.

43. Bruzzone R, Veronesi V, Gomès D, Bicego M, Duval N, Marlin S, et al. Loss-of-function and residual channel activity of connexin26 mutations associated with non-syndromic deafness. FEBS Lett. 2003;533:79-88.

44. Shen J, Oza AM, Del Castillo I, Duzkale H, Matsunaga T, Pandya A, et al. Consensus interpretation of the p.Met34Thr and p.Val37lle variants in GJB2 by the ClinGen Hearing Loss Expert Panel. Genet Med. 2019;21:2442-52.

45. Marlin S, Feldmann D, Blons H, Loundon N, Rouillon I, Albert S, et al. GJB2 and GJB6 mutations: genotypic and phenotypic correlations in a large cohort of hearing-impaired patients. Arch Otolaryngol Head Neck Surg. 2005;131:481-7.

46. Kenna MA, Wu BL, Cotanche DA, Korf BR, Rehm HL. Connexin 26 studies in patients with sensorineural hearing loss. Arch Otolaryngol Head Neck Surg. 2001;127:1037-42.

47. Cryns K, Orzan E, Murgia A, Huygen PL, Moreno F, del Castillo I, et al. A genotype-phenotype correlation for GJB2 (connexin 26) deafness. J Med Genet. 2004;41:147-54

48. Xu J, Nicholson BJ. The role of connexins in ear and skin physiology functional insights from disease-associated mutations. Biochim Biophys Acta. 2013;1828:167-78.

49. Ambrosi C, Walker AE, Depriest AD, Cone AC, Lu C, Badger J, et al. Analysis of trafficking, stability and function of human connexin 26 gap junction channels with deafness-causing mutations in the fourth transmembrane helix. PLoS ONE. 2013;8:e70916.

50. ClinVar. Bethesda: U.S. National Library of Medicine, National Center for Biotechnology Information; c2019-12. NM_004004.6(GJB2):c.71G>A (p.Trp24Ter). [accessed 2019 Jan 7]. Available from: https://www.ncbi. 
51. ClinVar. Bethesda: U.S. National Library of Medicine, National Center for Biotechnology Information; c2019-12. NM_004004.6(GJB2):c.550C>T (p.Arg184Trp). [accessed 2019 Jan 7]. Available from: https://www.ncbi. nlm.nih.gov/clinvar/variation/560669/.

52. ClinVar. Bethesda: U.S. National Library of Medicine, National Center for Biotechnology Information; c2019-12. NM_004004.6(GJB2):c.283G>A (p.Val95Met). [accessed 2019 Jan 7]. Available from: https://www.ncbi. nlm.nih.gov/clinvar/variation/44735/.
53. ClinVar. Bethesda: U.S. National Library of Medicine, National Center for Biotechnology Information; c2019-12. NM_004004.6(GJB2):c.428G>A (p.Arg143GIn). [accessed 2019 Jan 7]. Available from: https://www.ncbi. nlm.nih.gov/clinvar/variation/17017/.

54. ClinVar. Bethesda: U.S. National Library of Medicine, National Center for Biotechnology Information; c2019-12. NM_000503.6(EYA1):c.88A>G (p.lle30Val). [accessed 2019 Jan 7]. Available from: https://www.ncbi. nIm.nih.gov/clinvar/variation/517593/. 